\title{
NOTAS TAXONÔMICAS SOBRE PSEUDIS FUSCA GARMAN E P. BOLBODACTYLA A. LUTZ, COM A DESCRIÇÃO DE UMA NOVA ESPÉCIE CORRELATA (ANURA, PSEUDIDAE)
}

\author{
Ulisses Caramaschi ${ }^{1,3}$ \\ Carlos Alberto Gonçalves da Cruz ${ }^{2,3}$
}

\begin{abstract}
TAXONOMIC NOTES ON PSEUdIS FUSCA GARMAN AND P. BOLBODACTYLA A. Lutz, With dESCRIPTION OF a NEW CORRELATEd SPECIES (ANura, Pseudidae). The taxonomic status of Pseudis fusca Garman and $P$. bolbodactyla A. Lutz is revalidated, and here they are considered full species. The rediscovery of $P$. fusca is related, and a redescription of the species is presented. The redescription, the designation of the lectotype, and the description of the tadpole of $P$. bolbodactyla are provided. Pseudis tocantins sp.n. is described from the Tocantins river basin. The geographical distribution of these three species is discussed.

KEY WORDS. Anura, Pseudidae, Pseudis, taxonomy, geographical distribution
\end{abstract}

Atualmente o gênero Pseudis Wagler, 1830 compreende duas espécies, $P$. minuta Günther, 1858, distribuída nos estados de Santa Catarina e Rio Grande do Sul, Brasil, províncias de Buenos Aires, Santa Fé, Entre Rios e Corrientes, Argentina, e Uruguai (KLAPPENBACH 1985), e $P$. paradoxa (Linnaeus, 1758), que está subdividida em sete subespécies: P. p. paradoxa (Linnaeus, 1758), com distribuição amazônica, $P$. p. fusca Garman, 1883, restrita à bacia do rio Jequitinhonha, Minas Gerais, $P$. p. bolbodactyla A. Lutz, 1925, distribuida pelas bacias dos rios São Francisco e Doce, Minas Gerais, Bahia e Espírito Santo, P. p. caribensis Gallardo, 1961, registrada para a ilha de Trinidad e nordeste da Venezuela, $P$. $p$. platensis Gallardo, 1961, com distribuição na bacia dos rios Paraná-Paraguai, P. p. occidentalis Gallardo, 1961, conhecida apenas de El Pailón, Bolívia, e P. p. nicefori Cochran \& Goin, 1970, com ocorrência no norte da Colômbia (GALLARDO 1961; CocHRAN \& GoIN 1970).

O exame da literatura e de exemplares de diversas dessas subespécies permitiu o reconhecimento de dois grupos distintos. Um deles é caracterizado pela presença de um grande calo carpal arredondado, e envolve $P$. p. paradoxa, $P$. $p$. caribensis, $P$. p. platensis, $P$. p. occidentalis e $P$. p. nicefori. Por outro lado, a ausência ou a presença apenas vestigial do calo carpal caracteriza e separa prontamente o grupo formado por $P$. p. fusca e $P$. p. bolbodactyla do complexo de subespécies de $P$. paradoxa.

1) Departamento de Vertebrados, Museu Nacional. Quinta da Boa Vista, 20940-040 Rio de Janeiro, Rio de Janeiro, Brasil.

2) Departamento de Biologia Animal, Universidade Federal Rural do Rio de Janeiro. 23851-970 Seropédica, Rio de Janeiro, Brasil.

3) Bolsista do CNPq 
No presente trabalho são apresentadas notas sobre a taxonomia de $P$. fusca e $P$. bolbodactyla, aqui consideradas espécies plenas, envolvendo a redescrição de ambas, designação do lectótipo e descrição do girino de $P$. bolbodactyla e apresentação de suas distribuições geográficas. Além disso, uma nova espécie correlata é descrita da bacia do rio Tocantins. As subespécies restantes de $P$. paradoxa não serão abordadas.

\section{MATERIAL E MÉTODOS}

Acrônimos das coleções referidas: AL-MN (Coleção Adolpho Lutz, Museu Nacional, Rio de Janeiro, Rio de Janeiro); CFBH (Coleção Célio F.B. Haddad, Universidade Estadual Paulista, Campus de Rio Claro, São Paulo); MCN-AM (Museu de Ciências Naturais, Pontifícia Universidade Católica de Minas Gerais, Belo Horizonte, Minas Gerais); MCZ (Museum of Comparative Zoology, Harvard, USA); MNRJ (Museu Nacional, Rio de Janeiro, Rio de Janeiro); MZUSP (Museu de Zoologia, Universidade de São Paulo, São Paulo); USNM (United States National Museum, Smithsonian Institution, Washington, USA). Os exemplares examinados estão relacionados no final do tratamento de cada espécie.

Abreviaturas das medidas, em milímetros, utilizadas para exemplares adultos: CRA (comprimento rostro-anal); CC (comprimento da cabeça); LC (largura da cabeça); DIN (distância internasal); DNO (distância narina-olho); DO (diâmetro do olho); LPS (largura da pálpebra superior); DIO (distância interorbital); DT (diâmetro do tímpano); CCX (comprimento da coxa); CT (comprimento da tíbia); CTP (comprimento do tarso-pé).

Abreviaturas das medidas, em milímetros) utilizadas para girinos: CT (comprimento total); CRA (comprimento rostro-anal); AC (altura do corpo); DIN (distância internasal); DNO (distância narina-olho); DO (diâmetro do olho); DIO (distância interorbital); CCA (comprimento da cauda); ACA (altura da cauda); AND (altura da nadadeira dorsal); ANV (altura da nadadeira ventral); CTA (comprimento do tubo anal). Estágios de desenvolvimento referidos seguem GOSNER (1960). Nomenclatura das linhas sensitivas de acordo com NoBLE (1931) e VizotTo (1967).

\section{RESULTADOS}

\section{Pseudis fusca Garman, 1883 stat. rev.}

Pseudis fusca Garman, 1883; Nieden, 1923. - Miranda-Ribeiro, 1926. - Cochran, 1955.

Batrachichthys [sic] pizarronis Garman, 1883 (nomen nudum).

Pseudis paradoxus fuscus; Gallardo, 1961. - Gorham, 1974. - Duellman, 1977. - Harding, 1983.

Pseudis paradoxa fusca; Bokermann, 1966.

Diagnose. Espécie de tamanho médio para o gênero (CRA 35,7-40,8 mm nos machos; 40,7-46,2 mm nas fêmeas), diagnosticada pelo calo carpal apenas vestigial ou ausente, cabeça mais larga que longa, pele lisa no dorso do corpo e ausência de faixas na face ventral das coxas. 
Tipos e localidade-tipo. A espécie foi descrita com base em dois síntipos, MCZ 1872, coletados no "Rio Arassuahy, Brazil" (GARMAN 1883), em 1864-1867, por Hartt e Copeland, membros da Thayer Expedition (GALlARDO 1961). O rio Araçuaí ( $\left.16^{\circ} 46^{\prime} \mathrm{S}, 42^{\circ} 02^{\prime} \mathrm{W}\right)$, localidade-tipo da espécie, é um afluente da margem direita do rio Jequitinhonha, Minas Gerais, Brasil.

Descrição. Aspecto robusto (Figs 1-2), comprimento da cabeça menor que a largura, que cabe cerca de 2,5 vezes no comprimento total; focinho arredondado em vistas dorsal e lateral; narinas não protuberantes, elípticas, situadas dorsolateralmente e dirigidas para frente; distância internasal aproximadamente igual ou ligeiramente maior que a distância narina-olho, ligeiramente menor que a largura da pálpebra superior nos machos e maior nas fêmeas, e maior que a distância interorbital; olhos grandes, situados e dirigidos dorsolateralmente; diâmetro do olho ligeiramente maior que 1,5 vezes a distância narina-olho e pouco maior que $o$ diâmetro do tímpano; canto rostral arredondado, região loreal ligeiramente côncava; saco vocal subgular, simples; dentes vomerianos em dois grupos pequenos, entre as coanas, que são pequenas e circulares; língua grande, circular, pouco livre e não entalhada na porção posterior; tímpano evidente, aproximadamente elíptico, colocado muito próximo à borda posterior do olho; uma prega dérmica supratimpânica pouco evidente, que se prolonga até a inserção do braço.

Membros anteriores robustos, braço e antebraço aproximadamente da mesma espessura. Mão delgada, com calo carpal apenas vestigial ou ausente; superfície palmar rugosa; dedos livres, longos e finos, fimbriados; discos apicais ausentes; dedo I espessado até a metade de seu comprimento e com um calo grande, elíptico, na base; tubérculos subarticulares desenvolvidos, cônicos e simples; tubérculos supranumerários presentes.

Membros posteriores longos e robustos; comprimento da coxa pouco maior que o comprimento da tíbia; soma dos comprimentos da coxa e da tíbia cerca de 1,2 vezes o comprimento total. Pé com tubérculo metatarsal interno grande, alongado e livre na extremidade distal; tubérculo metatarsal externo ausente; uma forte prega dérmica ao longo da margem interna do tarso, prolongando-se como uma fímbria ao longo da borda externa do artelho I; artelhos longos e finos, ligeiramente dilatados na extremidade e completamente interligados por membranas interdigitais; borda externa do artelho V fimbriada; tubérculos subarticulares arredondados, simples; tubérculos supranumerários ausentes.

Superficies dorsais lisas, exceto na região do uróstilo e sobre as tíbias, onde aparecem diminutos tubérculos esparsos; superfícies ventrais lisas; região e abertura anal não modificadas.

Em preservativo (álcool $70^{\circ} \mathrm{GL}$ ), superfícies dorsais com colorido castanho ou cinza, com pequenas manchas mais escuras esparsas no corpo, sem formar desenho definido, e em forma de barras nas coxas e nas tíbias; uma faixa castanho escuro ou cinza ao longo da face ventrolateral do membro anterior; superfície ventral do corpo e das coxas creme uniforme, às vezes com pequenas manchas castanhas ou cinzentas esparsas, sem formar padrão de faixas nas coxas; faces posteriores das coxas com manchas irregulares castanhas ou cinzas; face interna da tíbia e do tarso com pequenas manchas castanhas ou cinzas esparsas; uma faixa castanho escuro ou 

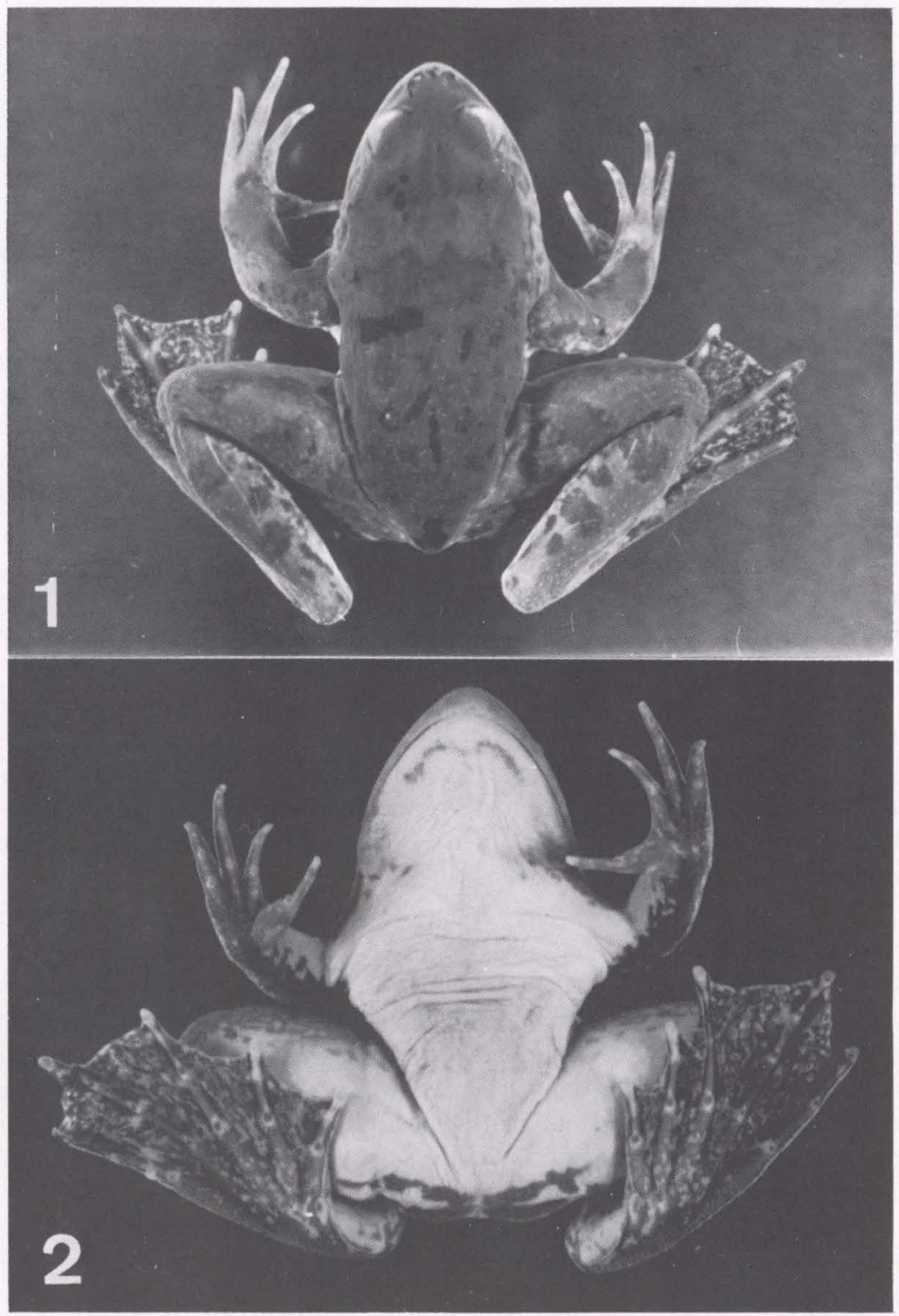

Figs 1-2. Pseudis fusca (MNRJ 17021). (1) Vista dorsal; (2) vista ventral.

cinza ao longo da face ventral do tarso; membranas interdigitais com fino marmoreado castanho ou cinza.

Variação. Existe pouca variação entre os exemplares examinados, a não ser detalhes de colorido e medidas (Tab. I).

Girino. Desconhecido. 
Tabela I. Amplitudes das medidas (em milímetros) de Pseudis fusca.

\begin{tabular}{lcc}
\hline \multirow{2}{*}{ Medidas } & Machos $(\mathrm{n}=2)$ & Fêmeas $(\mathrm{n}=2)$ \\
\cline { 2 - 3 } & Amplitude & Amplitude \\
\hline CRA & $35,7-40,8$ & $40,7-46,2$ \\
CC & $13,0-15,1$ & $15,0-16,0$ \\
LC & $14,6-16,1$ & $15,6-17,7$ \\
DIN & $3,0-3,0$ & $3,2-3,3$ \\
DNO & $2,7-3,0$ & $3,0-3,1$ \\
DO & $4,6-5,1$ & $5,0-5,0$ \\
LPS & $3,2-3,3$ & $3,1-3,2$ \\
DIO & $2,0-3,2$ & $2,3-3,3$ \\
DT & $4,3-4,4$ & $4,4-4,5$ \\
CCX & $23,2-26,6$ & $23,6-29,0$ \\
CT & $22,0-24,6$ & $23,4-27,4$ \\
CTP & $32,2-35,7$ & $33,6-39,6$ \\
\hline
\end{tabular}

Distribuição geográfica. Conhecida de duas localidades (Araçuaí e Salinas), Minas Gerais, associadas à bacia do rio Jequitinhonha (Fig. 3).

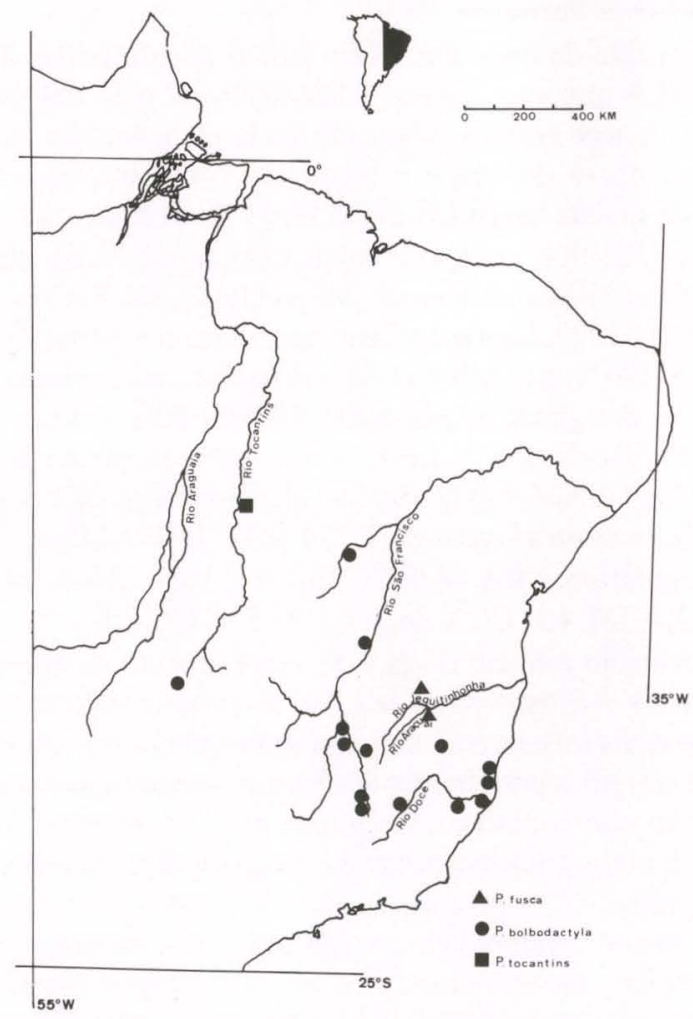

Fig. 3. Distribuição geográfica de Pseudis fusca, $P$. bolbodactyla e $P$. tocantins sp.n.. 
Observações. Até o presente, Pseudis fusca era conhecida apenas dos dois síntipos (MCZ 1872), coletados há mais de 130 anos. Essa espécie está restrita à bacia do rio Jequitinhonha, no nordeste de Minas Gerais.

GARMAN (1883), ao descrever $P$. fusca, considera que os exemplares que estudou poderiam ser representantes do estágio adulto de Batrachichthys [sic] pizarronis, sem maiores comentários. Desta forma, GARMAN (1883) criou um nomen nudum ligado a $P$. fusca, já que Batrachychthys Pizarro, 1876 (sem associação a nenhum nome específico) foi baseado em uma larva (MNRJ 76) proveniente de Potrero Pires (Paraguai), atualmente identificada como representante de $P$. paradoxa platensis.

Material examinado. BRAsiL, Minas Gerais: Salinas, VI-1990, G.A. Cotta leg., MNRJ 14127-14128; Araçuaí, 10-III-1990, L.B. Nascimento leg., MNRJ 17020-17021.

\section{Pseudis bolbodactyla A. Lutz, 1925, stat. rev.}

Pseudis bolbodactyla A. Lutz, 1925; Cochran, 1955.

Pseudis paradoxus bolbodactylus; Gallardo, 1961; Gorham, 1974; Duellman, 1977; Harding, 1983.

Pseudis paradoxa bolbodactyla; Bokermann, 1966.

Diagnose. Espécie de tamanho médio para o gênero (CRA 33,9-45,0 mm nos machos; 38,3-51,4 mm nas fêmeas), diagnosticada pelo calo carpal apenas vestigial ou ausente, cabeça aproximadamente tão larga quanto longa, pele acentuadamente rugosa no dorso do corpo e membros, com diminutos tubérculos, e presença de faixas castanhas longitudinais na face ventral das coxas.

Tipos e localidade-tipo. A espécie foi descrita com base em quatro síntipos: AL-MN 820, Lagoa Curralinho, Lassance, Minas Gerais, 04-X-1924, A. Lutz \& J. Venâncio leg.; USNM 97022, Lagoa do Genipapo, Lassance, Minas Gerais, A. Lutz leg. (CoCHRAN 1955, 1961); AL-MN 851-852, Belo Horizonte, Minas Gerais, 1924 , A. Lutz leg.. Aqui é designado o exemplar AL-MN 820, macho adulto, como lectótipo de Pseudis bolbodactyla A. Lutz, 1925 e, conseqüentemente, os exemplares AL-MN 851-852 e USNM 97022 são considerados paralectótipos. A localida-

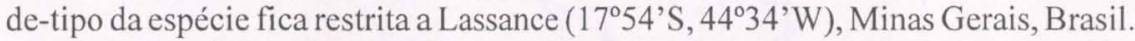

Medidas do lectótipo. CRA 44,0; CC 16,7; LC 16,6; DIN 2,3; DNO 3,0; DO 5,7; LPS 3,3; DIO 2,4; DT 4,1; CCX 26,3; CT 23,5; CTP 33,8.

Descrição. Aspecto robusto (Figs 4-5), comprimento da cabeça aproximadamente igual à largura, que cabe cerca de 2,7 vezes no comprimento total; focinho arredondado em vistas dorsal e lateral; narinas não protuberantes, elípticas, situadas dorsolateralmente e dirigidas para frente; distância internasal igual ou ligeiramente menor que a distância narina-olho e a largura da pálpebra superior, e maior que a distância interorbital; olhos grandes, situados e dirigidos dorsolateralmente; diâmetro do olho equivalente a 1,7 vezes a distância narina-olho e maior que o diâmetro do tímpano; canto rostral arredondado, região loreal ligeiramente côncava; saco vocal subgular, simples; dentes vomerianos em dois grupos pequenos, entre as coanas, que são pequenas e circulares; língua grande, circular, pouco livre e não entalhada na porção posterior; tímpano evidente, aproximadamente elíptico, colo- 

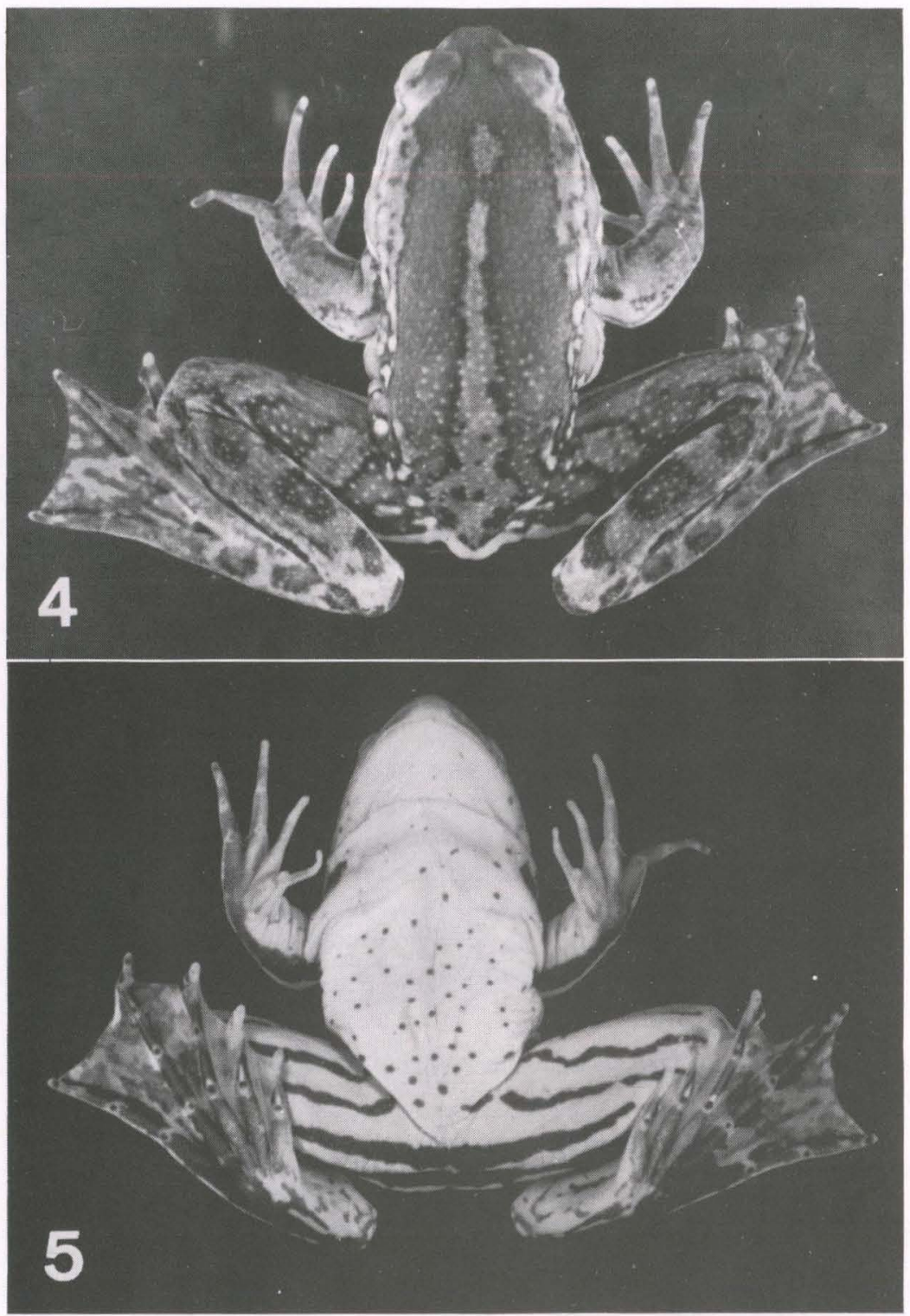

Figs 4-5. Pseudis bolbodactyla (MNRJ 14083). (4) Vista dorsal; (5) vista ventral.

cado muito próximo à borda posterior do olho; uma prega dérmica supratimpânica evidente, que se prolonga até a inserção do braço.

Membros anteriores robustos, braço e antebraço aproximadamente da mesma espessura. Mão delgada, com calo carpal apenas vestigial ou ausente; superfície palmar discretamente rugosa; dedos livres, longos e finos, fimbriados; discos apicais 
ausentes; dedo I espessado até a metade de seu comprimento e com um calo elíptico, pouco evidente, na base; tubérculos subarticulares desenvolvidos, cônicos e simples; tubérculos supranumerários presentes.

Membros posteriores longos e robustos; comprimento da coxa pouco maior que o comprimento da tíbia; soma dos comprimentos da coxa e da tíbia cerca de 1,2 vezes o comprimento total. Pé com tubérculo metatarsal interno grande, alongado e livre na extremidade distal; tubérculo metatarsal externo ausente; uma prega dérmica ao longo da margem interna do tarso até o tubérculo metatarsal; uma fímbria ao longo da borda externa do artelho I; artelhos longos e finos, ligeiramente dilatados na extremidade e completamente interligados por membranas interdigitais; borda externa do artelho V fimbriada; tubérculos subarticulares arredondados, simples; tubérculos supranumerários ausentes.

Superfícies dorsais acentuadamente rugosas, com grande número de diminutos tubérculos; superfícies ventrais dos antebraços e tarsos com acentuada presença de diminutos tubérculos; ventre com pequenas pregas transversais; regiões gular e peitoral, e faces inferiores das coxas, lisas; região e abertura anal não modificadas.

Em preservativo (álcool $70^{\circ} \mathrm{GL}$ ), superfícies dorsais com colorido castanho, com manchas mais escuras esparsas ou interligadas, sem formar desenho definido, no corpo, nas coxas e nas tíbias; uma faixa castanho escuro ao longo da face ventrolateral do membro anterior; superfície ventral do corpo creme uniforme, às vezes com pequenas manchas castanhas esparsas; faces posteriores e ventrais das coxas com estreitas faixas longitudinais castanhas; face interna da tíbia e do tarso com pequenas manchas castanhas esparsas; uma faixa castanho escuro ao longo da face ventral do tarso; membranas interdigitais com marmoreado castanho.

Variação. Existe pouca variação entre os exemplares examinados, a não ser detalhes de colorido e medidas (Tab. II). Um exemplar (MNRJ 18793) possui a região dorsal com rugosidade menos pronunciada e menor quantidade de pequenos tubérculos.

Tabela II. Amplitude, média e desvio-padrão (DP) das medidas (em milimetros) de Pseudis bolbodactyla.

\begin{tabular}{lrrrrrrrr}
\hline \multirow{2}{*}{ Medidas } & \multicolumn{3}{c}{ Machos $(n=16)$} & & & \multicolumn{3}{c}{ Fêmeas $(n=12)$} \\
\cline { 2 - 3 } \cline { 6 - 8 } & Amplitude & Média & DP & & Amplitude & Média & DP \\
\hline CRA & $33,9-45,0$ & 39,0 & 3,33 & & $38,3-51,4$ & 43,1 & 4,39 \\
CC & $12,5-16,7$ & 14,7 & 1,33 & & $13,3-20,3$ & 16,1 & 2,36 \\
LC & $12,4-16,6$ & 14,6 & 1,30 & & $14,1-21,4$ & 16,2 & 2,39 \\
DIN & $2,3-3,7$ & 2,9 & 0,44 & & $2,3-3,3$ & 2,9 & 0,32 \\
DNO & $2,4-3,5$ & 2,9 & 0,28 & & $2,9-3,8$ & 3,2 & 0,30 \\
DO & $4,2-5,8$ & 4,9 & 0,52 & & $4,3-6,1$ & 5,2 & 0,68 \\
LPS & $2,8-3,3$ & 2,9 & 0,19 & & $2,8-4,0$ & 3,3 & 0,31 \\
DIO & $2,0-3,1$ & 2,5 & 0,32 & & $2,4-3,1$ & 2,8 & 0,26 \\
DT & $3,5-4,4$ & 3,8 & 0,30 & & $3,8-4,8$ & 4,1 & 0,33 \\
CCX & $21,0-26,6$ & 23,5 & 1,73 & & $21,6-30,2$ & 25,2 & 2,96 \\
CT & $19,7-24,4$ & 22,2 & 1,59 & & $21,1-27,9$ & 24,0 & 2,25 \\
CTP & $27,1-36,2$ & 31,2 & 2,45 & & $28,1-38,0$ & 33,7 & 2,97 \\
\hline
\end{tabular}


Girino (Figs 6-9). MNRJ 14391. Estágio 39. Medidas: CT 129,6; CRA 38,5; AC 31,6; DIN 6,8; DNO 9,6; DO 4,2; DIO 18,7; CCA 98,6; ACA 31,6; AND 9,5; ANV 10,0; CTA 11,2.

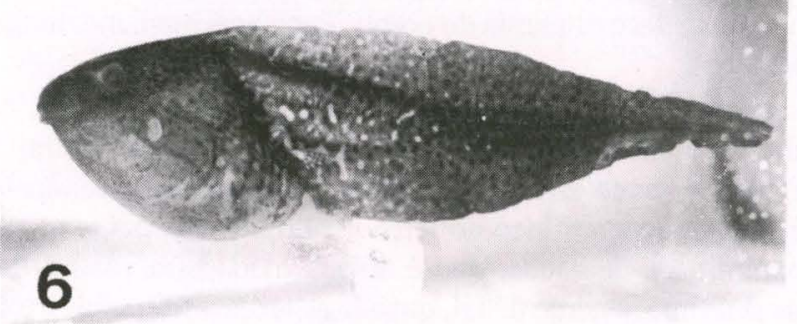

Fig. 6. Girino de Pseudis bolbodactyla, estágio 39 (MNRJ 14391), vista lateral.
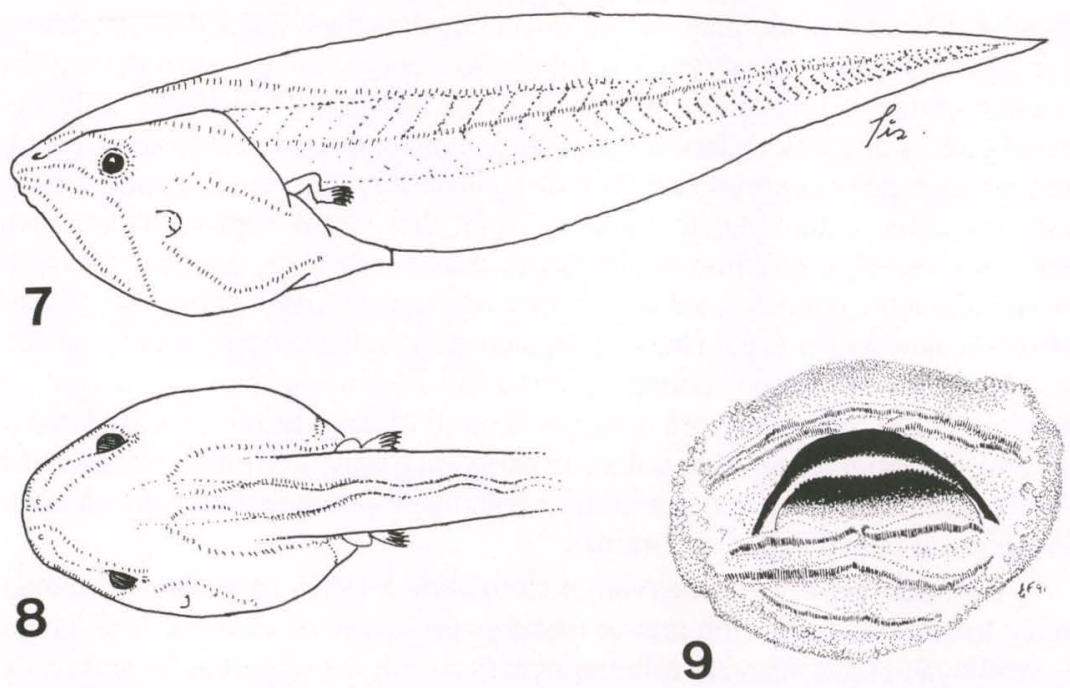

Figs 7-9. Girino de Pseudis bolbodactyla, estágio 39 (MNRJ 14391). (7) Esquema da disposição das linhas sensitivas em vista lateral; (8) esquema da disposição das linhas sensitivas em vista dorsal; (9) boca.

Corpo, em vista lateral, de contorno aproximadamente losangular; em vista dorsal, ovóide, com focinho arredondado; narinas elípticas, mais próximas da extremidade do focinho que dos olhos; distância internasal cabendo cerca de três 
vezes na distância interorbital; olhos dorsolaterais, pequenos, afastados da extremidade do focinho pouco mais do dobro de seu diâmetro; distância interorbital aproximadamente quatro vezes maior que o diâmetro ocular. Boca pequena, subterminal, margeada por uma fileira de papilas labiais pigmentadas e interrompida na margem anterior; dentículos córneos labiais dispostos segundo a fórmula 2(2) / $3(1)$; bicos córneos fortes, com as bordas finamente serrilhadas; peça superior com margem côncava e peça inferior aproximadamente reta. Espiráculo curto, aproximadamente no meio da face esquerda do corpo. Tubo anal mediano, longo e amplo; abertura anal mediana.

Cauda espessa, lanceolada, representando mais de dois terços do comprimento total; altura da nadadeira dorsal pouco menor que a da ventral; nadadeira dorsal com origem no terço anterior do corpo, de contorno ascendente na parte anterior, aproximadamente retilíneo no terço médio e descendente na porção posterior, até a extremidade da cauda, que é afilada; nadadeira ventral de contorno arredondado até próximo ao terço distal, quando se torna retilínea até a extremidade da cauda; musculatura caudal bem desenvolvida, com miômeros definidos, separados pelos mioseptos mais escuros.

Sistema de linhas sensitivas composto por fendas estreitas, alinhadas de cada lado do corpo; ramos dorsais paralelos entre si, separados pela crista da nadadeira, iniciam-se no plano de emergência da cauda e se estendem até o terço mediano desta; ramos laterais com início próximo ao início dos dorsais, arqueando-se para baixo sobre o terço posterior do corpo e seguindo pelo eixo muscular até a extremidade da cauda; ramos supra-orbitais iniciam-se na extremidade do focinho e dirigem-se para trás, até os ângulos posteriores dos olhos; ramos infra-orbitais partem da região bucal, passam por baixo das narinas e dirigem-se para trás, contornando inferiormente os olhos e terminando junto ao final dos ramos supra-orbitais; ramos angulares com início próximo aos bordos posteriores da boca, dirigem-se para trás aproximadamente paralelos aos ramos infra-orbitais até a altura dos olhos, quando curvam-se abruptamente para baixo e seguem até a região ventral; ramos orais com início junto aos bordos posteriores da boca, imediatamente abaixo da origem dos ramos angulares, dirigidos para a região ventral; ramos ventrais subdivididos em duas porções, sendo a superior colocada aproximadamente em linha horizontal no meio da face lateral do corpo, e a inferior com início próximo à base do espiráculo e dirigindo-se para a região abdominal.

Colorido geral, em preservativo (formalina a 10\%), castanho acinzentado; dorso e laterais do corpo com muitas manchas pequenas, de contorno arredondado e de coloração preta; manchas esbranquiçadas e manchas cinzentas na parte posterior do ventre e no tubo anal, sem formar desenho definido. Cauda com padrão de colorido semelhante ao corpo, mas mais claro; pequenas manchas escuras distribuidas por toda a extensão da cauda, diminuindo de tamanho da parte anterior para trás; eixo muscular marmoreado próximo à inserção da cauda e ao membro posterior; muitas manchas escuras no terço anterior e mediano da nadadeira superior; nadadeira inferior com manchas brancacentas na região próxima ao tubo anal e membro posterior, e diversas manchas escuras no restante de sua extensão. Os membros posteriores já exibem colorido semelhante ao adulto, constituído por 
quatro faixas castanhas na parte interna da coxa e manchas irregulares da mesma cor na face interna da tíbia.

Nos estágios 27 e 29, os girinos examinados apresentam CRA de 59,7 e 77,5 $\mathrm{mm}$, respectivamente; colorido do corpo cinza escuro e cauda com diversas manchas irregulares brancacentas. Quase ao final da metamorfose (estágio 44), o CRA diminui para $31,3 \mathrm{~mm}$ e o CCA para $88,5 \mathrm{~mm}$, a pele do dorso apresenta-se rugosa, e a membrana timpânica está pouco definida. O padrão de colorido, já igual ao do adulto, é constituído por duas faixas paralelas castanho-acinzentadas no dorso, separadas por outra mais clara; ventre com diversas manchas escuras arredondadas; quatro faixas longitudinais estreitas, castanhas, na região ventral da coxa; na tíbia, as manchas são de contorno irregular; cauda castanho-acinzentada, com considerável redução da massa muscular e das nadadeiras.

Das subespécies reconhecidas de Pseudis, foram descritas larvas de $P . p$. paradoxa (MIRANDA-RIBEIRO 1926; BOKERMANN 1967), P. p. platensis (PIZARRO 1876; Miranda-Ribeiro 1926; Gallardo 1964; Vizotto 1967; Cei 1980), P. p. occidentalis (GAllardo 1964; CEI 1980), P. p. nicefori (COCHRAN \& GOIN 1970) e P. minuta (FERnÁndez \& Fernández 1921; Gallardo 1964; Cei 1980). Além do formato geral e detalhes de colorido, o girino de $P$. bolbodactyla difere da larva de $P$. p. paradoxa, $P$. p. platensis e P. p. nicefori por ser menor $(130 \mathrm{~mm}$ CT em $P$. bolbodactyla e CT combinado das três subespécies entre 168 a $270 \mathrm{~mm}$ ), e de $P$. $p$. occidentalis e P. minuta por ser maior (117 mm CT em P. p. occidentalis e $68 \mathrm{~mm}$ CT em $P$. minuta). O girino de $P$. bolbodactyla possui as duas fileiras internas de dentículos córneos labiais interrompidas [fórmula 2(2) / 3(1)], enquanto que os girinos conhecidos do complexo de $P$. paradoxa possuem apenas a primeira fileira inferior interrompida [fórmula $2 / 3(1)$ ], e a larva de $P$. minuta possui apenas a primeira fileira superior interrompida [fórmula 2(1)/3].

Distribuição geográfica. Associada às áreas de influência das bacias dos rios São Francisco e Doce, nos estados de Minas Gerais, sul de Goiás, sul da Bahia e norte do Espírito Santo (Fig. 3).

Material examinado. BRASIL, Minas Gerais: Lassance, Lagoa do Curralinho, X-1924, A. Lutz \& J. Venâncio leg., AL-MN 820 (lectótipo); Belo Horizonte, 1924, A. Lutz leg. AL-MN $851-852$ (paralectótipos); Lassance, 1935, D.M. Cochran \& J. Venâncio leg. AL-MN 2581-2583; Lassance (Lagoa Curralinho), 1935, D.M. Cochran leg., AL-MN 2584-2586; Belo Horizonte, I-1954, A. Machado leg., MZUSP 15876; 14194-14195; Pirapora, 12-II-1942, Bailey \& A.L. Carvalho leg., MNRJ 3333, 14191; 14-II-1942, MNRJ 3318, 14134-14140; 18-XI-1987, G. Kisteumacher, M. Porto \& E. Carellos leg., MNRJ 14124-14126; Manga (Mocambinho), VIII-1990, E. Carellos leg., MNRJ 14022-14027; XI-1989, M. Porto \& L.C. Carcerelli leg., MNRJ 14028-14029; 26-27-IX-1990, U. Caramaschi \& G. Kisteumacher leg., MNRJ 14036-14121; 24-VI-1992, G. Kisteumacher leg., MNRJ 15907; 01-IX-1989, L.B. Nascimento leg., MCN-AM 107-112; Diamantina (Distrito de Conselheiro Mata, Fazenda Cunha), 12-14-VIII-1990, H.E.S. Melo leg., MCN-AM 556-557; Augusto de Lima (Fazenda Canabrava), 27-X-1990, H.E.S. Melo leg., MCN-AM 558; Manga, Mocambinho, IX-1990, D.F. Moraes Jr. leg., MNRJ $14391-14394$ (girinos); 24-VIII-1990, D.F. Moraes Jr. \& J.C. de Oliveira 
leg., MNRJ 15897-15898 (girinos); Marliéria (Parque Estadual do Rio Doce), 08-10-XI-1985, G. Kisteumacher leg., MNRJ 15899; Arinos, 14-XII-1986, M. Rodrigues leg., MZUSP 64518-64520; Teófilo Otoni, 17-XI-1969, W.C.A. Bokermann, F.M. Oliveira \& B.D. Silva leg., MZUSP 80408-80411. Goiás: Mossâmedes (Fazenda Poço d'Água), 04-XII-1997, J.P. Pombal Jr. \& R.P. Bastos leg., MNRJ 21808-21812. Bahia: Barreiras, 11-III-1942, Carvalho \& Bailey leg., MNRJ 2698. Espirito Santo: Linhares, Sooretama \& A.L. Carvalho leg., MNRJ 2692; São Mateus, 08-18-VII-1991, C. Zamprogno, R.P. Bastos \& R. Cometti leg., MNRJ 18792-18793; Itapina, 03-II-1934, W.S. Salgueiro leg., MZUSP 12616; São Mateus, 09-18-II-1992, R.P. Bastos \& C. Zamprogno leg., CFBH 1983-1985; Conceição da Barra (Vila de Itaunas), 26-31-I-1994, R.P. Bastos, J.P. Pombal Jr., J.L. Gasparini \& S. Recla leg., CFBH 2428-2430.

\section{Pseudis tocantins sp.n.}

Holótipo. MNRJ 11338, fêmea, coletado em Porto Nacional ( $10^{\circ} 42^{\prime} \mathrm{S}$, $48^{\circ} 25^{\prime} \mathrm{W}, 212 \mathrm{~m}$ altitude), margem direita do rio Tocantins, Tocantins, Brasil, VIII-1947, Green leg..

Parátipos. MNRJ 2481, 11339-11342, coletados com o holótipo.

Diagnose. Espécie de tamanho médio para o gênero (CRA 35,8-37,7 mm nas fêmeas), diagnosticada pelo calo carpal apenas vestigial ou ausente, cabeça mais longa que larga, pele lisa no dorso do corpo e presença de faixas castanhas muito estreitas na face ventral das coxas.

Descrição. Aspecto robusto (Figs 10-11), comprimento da cabeça maior que a largura, que cabe cerca de 2,2 vezes no comprimento total; focinho arredondado em vistas dorsal e lateral; narinas não protuberantes, elípticas, situadas dorsolateralmente e dirigidas para frente; distância internasal menor que a distância narinaolho e que a largura da pálpebra superior, e aproximadamente igual à distância interorbital; olhos grandes, situados e dirigidos dorsolateralmente; diâmetro do olho ligeiramente maior que 1,7 vezes a distância narina-olho e maior que o diâmetro do tímpano; canto rostral arredondado, região loreal ligeiramente côncava; dentes vomerianos em dois grupos pequenos, entre as coanas, que são pequenas e circulares; língua grande, circular, pouco livre e não entalhada na porção posterior; tímpano evidente, aproximadamente elíptico, colocado muito próximo à borda posterior do olho; uma prega dérmica supratimpânica pouco evidente.

Membros anteriores robustos, braço e antebraço aproximadamente da mesma espessura. Mão delgada, com calo carpal apenas vestigial ou ausente; superfície palmar lisa; dedos livres, longos e finos, fimbriados; discos apicais ausentes; dedo I espessado até a metade de seu comprimento e com um calo elíptico, pouco evidente, na base; tubérculos subarticulares desenvolvidos, cônicos e simples; tubérculos supranumerários ausentes.

Membros posteriores longos e robustos; comprimento da coxa pouco menor que o comprimento da tíbia; soma dos comprimentos da coxa e da tíbia cerca de 1,2 vezes o comprimento total. Pé com tubérculo metatarsal interno grande, alongado e livre na extremidade distal; tubérculo metatarsal externo ausente; uma prega 

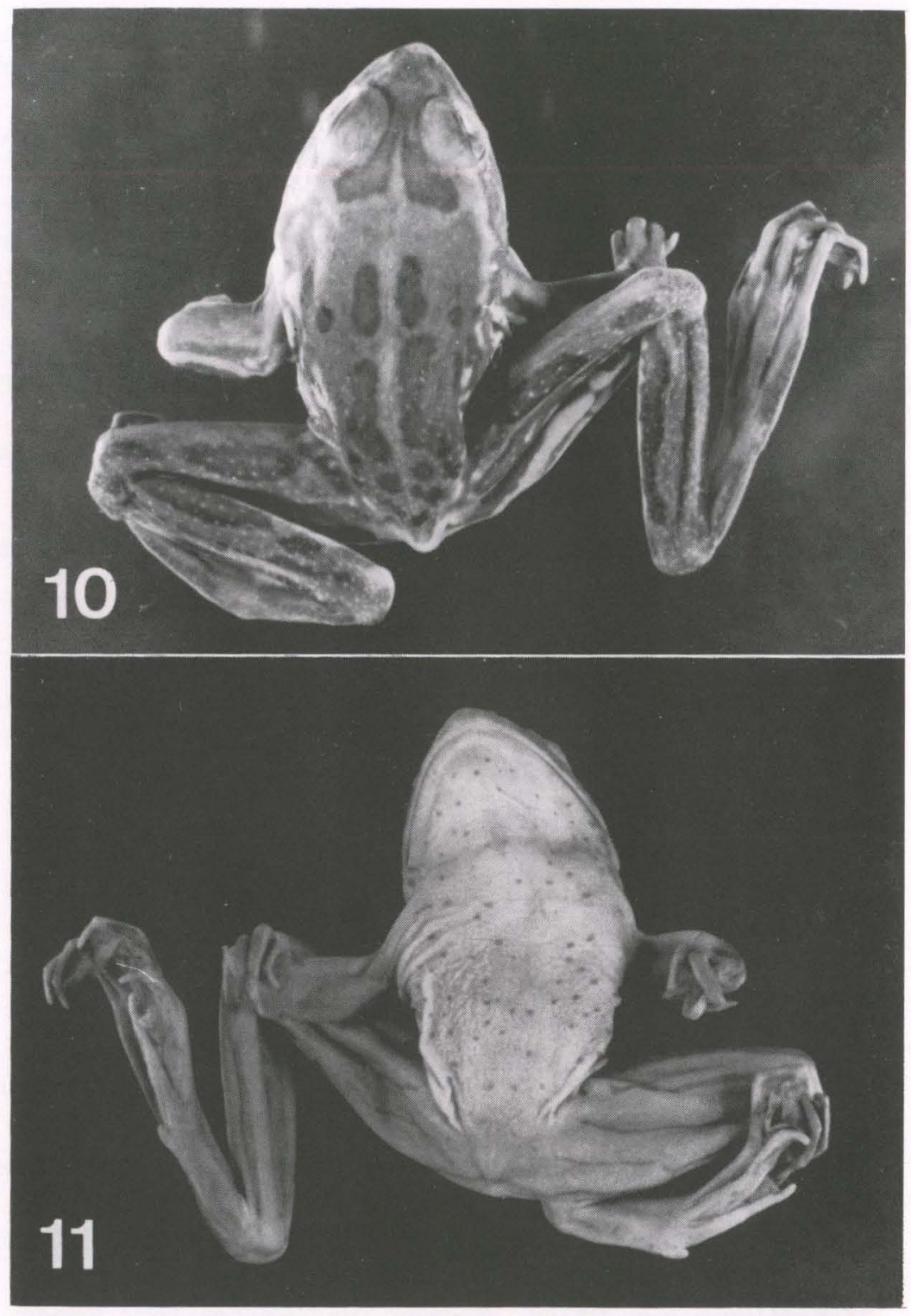

Figs 10-11. Pseudis tocantins sp.n. holótipo (MNRJ 11338). (10) Vista dorsal; (11) vista ventral.

dérmica ao longo da margem interna do tarso até o tubérculo metatarsal; uma fímbria ao longo da borda externa do artelho I; artelhos longos e finos, ligeiramente dilatados na extremidade e completamente interligados por membranas interdigitais; borda externa do artelho V fimbriada; tubérculos subarticulares arredondados, simples; tubérculos supranumerários ausentes. 
Superfícies dorsais lisas, exceto na região do uróstilo e sobre as coxas e tíbias, onde aparecem diminutos tubérculos; superfícies ventrais lisas; região e abertura anal não modificadas.

Em preservativo (álcool $70^{\circ} \mathrm{GL}$ ), superfícies dorsais com colorido castanho claro, com manchas castanho escuro irregularmente distribuídas no corpo, nas coxas e nas tíbias; uma faixa castanho escuro ao longo da face ventrolateral do membro anterior; superfície ventral do corpo e das coxas creme uniforme, às vezes com pontos castanhos esparsos; faces posteriores das coxas com estreitas faixas longitudinais castanhas e faces ventrais das coxas com faixas ainda mais estreitas, do mesmo colorido; face interna da tíbia com finas faixas longitudinais castanhas; uma faixa castanho escuro ao longo da face ventral do tarso; membranas interdigitais com marmoreado castanho.

Variação. Existe pouca variação entre os exemplares examinados, a não ser detalhes de colorido e medidas (Tab. III).

Tabela III. Amplitude, média e desvio-padrão (DP) das medidas (em milímetros) de Pseudis tocantins sp.n.

\begin{tabular}{lrcc}
\hline \multirow{2}{*}{ Medidas } & \multicolumn{3}{c}{ Fêmeas $(n=4)$} \\
\cline { 2 - 4 } & Amplitude & Média & DP \\
\hline CRA & $35,8-37,7$ & 36,8 & 0,91 \\
CC & $15,6-17,5$ & 16,5 & 0,89 \\
LC & $13,6-16,6$ & 15,4 & 1,34 \\
DIN & $2,2-2,8$ & 2,6 & 0,26 \\
DNO & $2,6-3,6$ & 3,1 & 0,47 \\
DO & $5,1-5,8$ & 5,4 & 0,32 \\
LPS & $2,7-3,2$ & 3,0 & 0,25 \\
DIO & $2,4-3,0$ & 2,6 & 0,26 \\
DT & $3,8-4,4$ & 4,1 & 0,23 \\
CCX & $20,0-24,1$ & 21,2 & 1,91 \\
CT & $20,3-24,3$ & 22,6 & 1,67 \\
CTP & $30,5-34,9$ & 33,2 & 1,98 \\
\hline
\end{tabular}

Girino. Desconhecido.

Distribuição geográfica. Conhecida apenas da localidade-tipo, Tocantins, associada à bacia do rio Tocantins (Fig. 3).

Etimologia. O epíteto específico, um nome em aposição, refere-se ao Estado e bacia do Tocantins, onde a espécie foi coletada.

Material examinado. BRASIL, Tocantins: (rio Tocantins, Porto Nacional), VIII-1947, Green leg., MNRJ 11338 (holótipo), MNRJ 2481, $11339-11342$ (parátipos).

\section{Comentários}

Pseudis fusca, P. bolbodactyla e P. tocantins possuem calo carpal externo ausente ou apenas vestigial, o que as separa prontamente dos outros componentes do gênero Pseudis associados ao complexo de $P$. paradoxa, que apresentam aquele 
calo bem desenvolvido; as três espécies, por sua vez, se separam de $P$. minuta por possuírem saco vocal simples, subgular, ao invés de saco vocal duplo, lateral.

A cabeça de $P$. fusca é mais larga que longa, ao passo que é tão longa quanto larga em $P$. bolbodactyla e mais longa que larga em $P$. tocantins. A pele do dorso é acentuadamente rugosa em $P$. bolbodactyla, ao passo que apresenta-se lisa nas outras duas espécies. A face ventral da coxa de $P$. fusca não apresenta faixas longitudinais, enquanto que estas são evidentes nas outras duas espécies, sendo que $P$. bolbodactyla apresenta faixas longitudinais castanhas largas e $P$. tocantins as apresenta bem estreitas.

As três espécies estudadas são alopátricas e apresentam nítida associação a bacias hidrográficas distintas. Assim, $P$. fusca está relacionada à bacia do rio Jequitinhonha, na região nordeste do de Minas Gerais e sul da Bahia. Entretanto, a espécie presentemente é conhecida apenas de duas localidades, na porção média daquela bacia. Por sua vez, ainda que a bacia do rio São Francisco se estenda desde o sul de Minas Gerais até os estados de Sergipe e Alagoas, passando pela Bahia, $P$. bolbodactyla está associada a suas porções alta e média, nos estados de Minas Gerais e Bahia, chegando ao sul de Goiás; quanto à bacia do rio Doce, que se estende pelo leste de Minas Gerais e norte do Espírito Santo, a espécie tem distribuição bastante abrangente. Ainda que as áreas de ocorrência de $P$. fusca e $P$. bolbodactyla estejam bastante próximas em alguns locais, entre elas existe a Serra do Espinhaço, que isola completamente as bacias dos rios São Francisco e Jequitinhonha. Já P. tocantins ocorre na porção média da bacia do rio Tocantins, a qual se estende pelos estados de Goiás, Tocantins, Maranhão e Pará. É previsível que esta espécie também ocorra na bacia do rio Araguaia, que está associada à do rio Tocantins.

AGRADECIMENTOS. A Paulo E. Vanzolini (MZUSP), Célio F.B. Haddad (CFBH) e Luciana B. Nascimento (MCN-AM), pelo acesso aos exemplares depositados nas coleções a seus cuidados. A Eleine Francioni, por informações e desenhos do girino de $P$. bolbodactyla. A José P. Pombal Jr. (MNRJ), pela leitura crítica do manuscrito.

\section{REFERÊNCIAS BIBLIOGRÁFICAS}

Bokermann, W.C.A. 1966. Lista Anotada das Localidades Tipo de Anfíbios Brasileiros. São Paulo, Serviço de Documentação, Reitoria da Universidade de São Paulo, 183p.

1967. Girinos de anfíbios brasileiros. 3: Sôbre um girino gigante de

"Pseudis paradoxa" (Amphibia, Pseudidae). Rev. Brasil. Biol. 27 (3): 209-212. CEI, J.M. 1980. Amphibians of Argentina. Monitore Zool. Ital. (N.S.) Monog. 2: $\mathrm{XII+609.}$

Cochran, D.M. 1955. Frogs of Southeastern Brazil. U.S. Nat. Mus. Bull. 206: $\mathrm{XVI}+423$.

National Museum. U.S. Nat. Mus. Bull. 220: XV+291.

Cochran, D.M. \& C.J. GoIN. 1970. Frogs of Colombia. U.S. Nat. Mus. Bull. 288: $\mathrm{XII}+655$. 
Duellman, W.E. 1977. Liste der rezenten Amphibien und Reptilien -Hylidae, Centrolenidae, Pseudidae. Das Tierreich 95: XIX+225.

FERnÁNDEZ, K. \& M. FernÁndez. 1921. Sobre la biologia y reproducción de algunos batracios argentinos (II). Bol. Acad. Nac. Cienc. Cordoba 29: 217-328. Gallardo, J.M. 1961. On the species of Pseudidae (Amphibia, Anura). Bull. Mus.

Comp. Zool. Harvard 125 (4): 111-134. . 1964. Una nueva forma de Pseudidae (Amphibia, Anura) y algunas consideraciones sobre las especies argentinas de esta familia. Acta Zool. Lilloana 20: 193-209.

Garman, S. 1883. A species of Pseudis, from the rio Arassuahy, Brazil. Science Observer 4 (5-6): 47.

GorHAM, S.W. 1974. Checklist of World Amphibians up to January 1, 1970. Saint John, Lingley Printing C. Ltd., 173p.

GosNER, K.L. 1960. A simplified table for staging anuran embryos and larvae with notes on identification. Herpetologica 16: 183-190.

HARDING, K.A. 1983. Catalogue of New World Amphibians. Oxford, Pergamon Press, XIV+406p.

KlapPenBaCH, M.A. 1985. Notas herpetologicas, V. Com. Zool. Mus. Hist. Nat. Montevideo 11 (150): 1-23.

LuTZ, A. 1925. Batraciens du Brésil. C.R. Soc. Biol. 93 (21): 137-139.

MIRANDA-RIBEIRO, A. 1926. Notas para servirem ao estudo dos gymnobatrachios

(Anura) brasileiros. Arq. Mus. Nac. Rio de Janeiro 27: 1-227.

NiEDEN, F. 1923. Anura I. Subordo Aglossa und Phaneroglossa. Sectio 1 Arcifera. Das Tierreich 46: XXXII+ 584.

NoBlE, G.K. 1931. The Biology of the Amphibia. New York, McGraw Hill Book Co., Inc., XIII+577p.

PiZARRo, J.J. 1876. Nota descriptiva de um pequeno animal extremamente curioso e denominado Batrachychthys. Arch. Mus. Nac. Rio de Janeiro 1: 31-35.

VizotTo, L.D. 1967. Desenvolvimento de anuros da região norte-ocidental do Estado de São Paulo. Fac. Filos. Ciênc. Letras São José do Rio Preto, Zoologia ( $\mathrm{n}^{\circ}$. especial): 1-161. 